\title{
Spinal Synthesis of Estrogen and Concomitant Signaling by Membrane Estrogen Receptors Regulate Spinal $\kappa$ - and $\mu$-Opioid Receptor Heterodimerization and Female-Specific Spinal Morphine Antinociception
}

\author{
Nai-Jiang Liu, ${ }^{1 *}$ Sumita Chakrabarti, ${ }^{1 *}$ Stephen Schnell, ${ }^{2}$ Martin Wessendorf, ${ }^{2}$ and Alan R. Gintzler ${ }^{1}$ \\ ${ }^{1}$ State University of New York, Downstate Medical Center, Brooklyn, New York 11203, and 2University of Minnesota, Minneapolis, Minnesota 55455
}

We previously demonstrated that the spinal cord $\kappa$-opioid receptor (KOR) and $\mu$-opioid receptor (MOR) form heterodimers (KOR/ MOR). KOR/MOR formation and the associated KOR dependency of spinal morphine antinociception are most robust during proestrus. Using Sprague Dawley rats, we now demonstrate that (1) spinal synthesis of estrogen is critical to these processes, and (2) blockade of either estrogen receptor (ER) $\alpha$-, $\beta$-, or G-protein-coupled ER1 or progesterone receptor (PR) substantially reduces KOR/MOR and eliminates mediation by KOR of spinal morphine antinociception. Effects of blocking ERs were manifest within $15 \mathrm{~min}$, whereas those of PR blockade were manifest after $18 \mathrm{~h}$, indicating the requirement for rapid signaling by estrogen and transcriptional effects of progesterone. Individual or combined blockade of ERs produced the same magnitude of effect, suggesting that they work in tandem as part of a macromolecular complex to regulate KOR/MOR formation. Consistent with this inference, we found that KOR and MOR were coexpressed with ER $\alpha$ and G-protein-coupled ER1 in the spinal dorsal horn. Reduction of KOR/MOR by ER or PR blockade or spinal aromatase inhibition shifts spinal morphine antinociception from KOR dependent to KOR independent. This indicates a sex steroiddependent plasticity of spinal KOR functionality, which could explain the greater analgesic potency of KOR agonists in women versus men. We suggest that KOR/MOR is a molecular switch that shifts the function of KOR and thereby endogenous dynorphin from pronociceptive to antinociceptive. KOR/MOR could thus serve as a novel molecular target for pain management in women.

\section{Introduction}

We demonstrated previously that $\kappa$-opioid receptors (KORs) and $\mu$-opioid receptors (MORs) form heterodimers (KOR/MOR) in spinal cord (Chakrabarti et al., 2010). Levels of KOR/MOR are approximately fourfold greater in the spinal cord of proestrus versus male rats (Chakrabarti et al., 2010), which results in sexually dimorphic antinociceptive responsiveness to spinal morphine (Liu et al., 2007; Chakrabarti et al., 2010). This sexual dimorphism results from activational actions of sex steroids because the spinal cord content of $\mathrm{KOR} / \mathrm{MOR}$ is substantially higher in spinal cord of proestrus versus diestrus rats (Chakrabarti et al., 2010). Given that circulating levels of $17-\beta$-estradiol [estrogen (E2)] as well as progesterone $\left(\mathrm{P}_{4}\right)$ vary in tandem across the estrous cycle, either or both steroids could modulate levels of KOR/MOR.

Several signaling strategies could mediate the ability of E2 and $\mathrm{P}_{4}$ to modulate KOR/MOR formation. Effects of $\mathrm{E} 2$ and $\mathrm{P}_{4}$ were

\footnotetext{
Received April 11, 2011; revised June 1, 2011; accepted June 22, 2011.

Author contributions: N.-J.L., S.C., S.S., M.W.W., and A.R.G. designed research; N.-J.L., S.C., S.S., M.W.W., and A.R.G. performed research; N.-J.L.,S.C., S.S., M.W.W., and A.R.G. analyzed data; N.-J.L., S.C., S.S., M.W.W., and A.R.G. wrote the paper.

${ }^{*}$ N.-J.L. and S.C. contributed equally to this work.

The authors declare no competing financial interests.

Correspondence should be addressed to Alan Gintzler, State University of New York, Downstate Medical Center, 450 Clarkson Avenue, Brooklyn, NY 11203. E-mail: alan.gintzler@downstate.edu.

DOI:10.1523/JNEUROSCI.1901-11.2011

Copyright $\odot 2011$ the authors $\quad 0270-6474 / 11 / 3111836-10 \$ 15.00 / 0$
}

originally thought to result exclusively from the ability of their respective receptors to function as $\mathrm{E} 2$ - and $\mathrm{P}_{4}$-activated transcription factors (Couse and Korach, 1999; Leonhardt et al., 2003). Recently, however, $\mathrm{E} 2$ and $\mathrm{P}_{4}$ signaling was discovered that differs from the classical mechanism in its temporal profile (seconds/minutes vs hours/days), subcellular localization (plasma membrane vs nucleus), and physiological consequences (modulation of second messengers and cell membrane signaling cascades vs expression of targeted proteins).

Estrogen receptor (ER) $\alpha$ and ER $\beta$, in addition to their nuclear localization, traffic to the plasma membrane (subsequent to being palmitoylated) (Levin, 2009) in which they associate with G-proteins (Mermelstein, 2009; Micevych and Dominguez, 2009) and mediate activation of multiple membrane signaling cascades (Vasudevan and Pfaff, 2008). An orphan G-proteincoupled receptor termed G-protein-coupled ER1 (GPER, aka GPR30) is also thought to be a plasma membrane ER (Filardo et al., 2000; Revankar et al., 2005). GPR30, unlike ER $\alpha$ and ER $\beta$, belongs to the G-protein-coupled seven-membrane-spanning receptor family (Bonini et al., 1997; Carmeci et al., 1997; Feng and Gregor, 1997; Takada et al., 1997). Typical of this receptor family, E2-activated GPR30 increases adenylyl cyclase activity [via generation of $G \alpha_{\mathrm{s}} / \mathrm{G} \beta \gamma$ (Thomas et al., 2005)] and other well-known membrane signaling cascades within seconds to minutes (Filardo et al., 2008). Analogously, there is increasing evidence that $P_{4}$ has rapid, membrane-initiated effects independent of gene transcrip- 
tion, which alter second-messenger production and activate signaling pathways (Leonhardt et al., 2003; Labombarda et al., 2010).

To investigate the role of spinal sex steroids in modulating expression levels of KOR/MOR and female-specific KORdependent spinal morphine antinociception, we determined the effects of inhibiting spinally synthesized E2 and blocking progesterone receptors $(\mathrm{PR})$ as well as specific types of ER, alone and in combination. Results indicate that analgesic mechanisms activated by spinal morphine are profoundly influenced by (1) locally synthesized E2, (2) rapid membrane-initiated ER signaling, and (3) transcriptional activation by $\mathrm{P}_{4}$. Our finding that the enhanced expression of KOR/MOR and the female-specific KOR-dependent spinal morphine antinociception require the concomitant activation of multiple types of membrane ERs indicates that they function in tandem as part of an interactive signaling complex.

\section{Materials and Methods}

Animals. We used proestrus rats (225-250 g, Sprague Dawley; Charles River) in the current study because spinal KOR/MOR formation and the KOR-dependent spinal morphine antinociception are much more robust in proestrus versus diestrus rats (Chakrabarti et al., 2010). Rats were maintained in an approved controlled environment on a $12 \mathrm{~h}$ light/dark cycle. Food and water were available ad libitum. All experimental procedures were reviewed and approved by the Animal Care and Use Committees of State University of New York Downstate Medical Center.

Implantation of intrathecal cannula. A permanent indwelling cannula was inserted into the lumbar spinal cord subarachnoid space under sodium pentobarbital anesthesia (40 mg/kg, i.p.; Abbott Laboratories) as described and routinely performed in this laboratory (Liu et al., 2007). In brief, a saline-filled catheter (PE-10; Clay Adams) was inserted through an incision in the atlanto-occipital membrane, slowly introduced into the spinal cord subarachnoid space $(8.0 \mathrm{~cm})$, and secured in place. The cephalic portion of the catheter was externalized through the skin above the skull area in which it was relatively inaccessible to the paws. Cannula placement and reliability of drug application to targeted areas were confirmed in pilot experiments using dye injection and visual inspection of cannula placement. Only animals that appeared to be free of infection during gross inspection were used. Motor integrity was assessed in all experimental groups by using the righting reflex and the inclined plane test. Those exhibiting motor impairment after surgery were eliminated from the study. All experiments were conducted within 2 weeks after surgery.

Determination of stage of estrous cycle. Histology of vaginal smears was used to evaluate stage of cycle. Predominance of large round nucleated cells indicated proestrus. Disruptions of the estrous cycle that could result from surgery did not confound data interpretation because vaginal smear histology, not predictions that assumed regularity of cycling, was used to define diestrus and proestrus.

Intrathecal administration of drugs. Nor-binaltorphimine (nor-BNI) and morphine (NIDA) were dissolved in $10 \mu \mathrm{l}$ of water and saline, respectively. Mifepristone (PR antagonist), fadrozole (aromatase inhibitor), 1,3-Bis(4-hydroxyphenyl)-4-methyl-5-[4-(2-piperidinylethoxy)phenol]-1Hpyrazole dihydrochloride (MPP) (ER $\alpha$-selective antagonist), 4-[2-phenyl-5,7bis(trifluoromethyl)pyrazol-o[1,5-a]pyrimidin-3-yl] phenol (PHTPP) (ER $\beta$-selective antagonist), ICI 182,780 (7 $\alpha, 17 \beta$-[9-[(4,4,5,5,5-pentafluoropentyl)sulfinyl] nonyl] estra-1,3,5(10)-triene-3,17-diol) (ER $\alpha$ and $\mathrm{ER} \beta$ antagonist), and G-15 (GPR30 antagonist) were each dissolved in 3 $\mu \mathrm{l}$ of DMSO. All drugs were obtained from Tocris Bioscience except for fadrozole, which was obtained from Sigma. Drugs were applied to the spinal cord subarachnoid space over a $60 \mathrm{~s}$ period via a permanent indwelling intrathecal cannula. Complete delivery was ensured by flushing the cannula with an additional $10 \mu \mathrm{l}$ of saline. The higher doses of ER and PR antagonists were calculated to be $1 \%$ of those reported for systemic administration. Lower doses were calculated based on estimated concentrations that would be achieved in the intrathecal space relative to reported selectivity and $K_{\mathrm{i}}$ values.
Assessment of tail-flick latency. Nociceptive response thresholds were assessed using radiant heat as the nociceptive stimulus. Tail-flick latency (TFL) was quantified by using a Tail Flick Analgesia Meter (IITC). Intensity of the radiant heat was adjusted such that baseline values were in the range of 3.5-4.5 s. A cutoff of $10 \mathrm{~s}$ latency prevented any untoward consequences to the tail. Data were expressed as either the absolute TFL value or as a percentage of maximal possible effect (MPE) $[\% \mathrm{MPE}=$ (experimental TFL - basal TFL $) /(10-$ basal TFL $) \times 100]$. No differences in basal TFL $(3.99 \pm 0.06 \mathrm{~s} ; n=96)$ were observed among control and experimental groups.

Membrane preparation, immunoprecipitation, and Western blot analysis. Spinal cord membranes were prepared and solubilized as described previously by this laboratory (Chakrabarti et al., 2010). Briefly, animals were killed by decapitation; spinal tissue was homogenized in $20 \mathrm{~mm}$ HEPES, pH 7.4, containing 10\% sucrose, 5 mм EDTA, 1 mm EGTA, 2 mm dithiothreitol, and multiple protease inhibitors, [ $1 \mathrm{~mm}$ benzamidine, 0.2 $\mathrm{g} / \mathrm{L}$ Bacitracin, $2 \mathrm{mg} / \mathrm{L}$ aprotinin, $3.2 \mathrm{mg} / \mathrm{L}$ each of leupeptin and trypsin inhibitor from soybean, $20 \mathrm{mg} / \mathrm{L}$ each of $\mathrm{N}$-tosyl-L-phenylalanine chloromethyl ketone, $\mathrm{N} \alpha$-Tosyl-L-lysine chloromethyl ketone, and phenylmethylsulfonyl fluoride, and complete cocktail inhibitor tablet $(50 \mathrm{ml}$; Roche Molecular Biochemicals)]. Supernatants from a low-speed spin $(1000 \times g$ for $10 \mathrm{~min})$ were centrifuged at a higher speed $(30,000 \times g)$ for $40 \mathrm{~min}$ to obtain membrane pellets. Immunoprecipitates were obtained from membranes solubilized in the above buffer containing $150 \mathrm{~mm}$ $\mathrm{NaCl}, 1 \%$ Nonidet P-40, 0.5\% Na-deoxycholate, $0.1 \% \mathrm{Na}$-dodecyl sulfate, and $10 \%$ glycerol, agitated $60 \mathrm{~min}$ at $4^{\circ} \mathrm{C}$, and centrifuged $(16,000 \times$ $g$ for $40 \mathrm{~min}$ at $4^{\circ} \mathrm{C}$ ). Immunoprecipitates to be compared were always obtained and processed in parallel. Two sequential immunoprecipitation (IP) procedures were performed by using an N-terminally directed antiKOR antibody (amino acids 1-70; Santa Cruz Biotechnology) as reported previously (Chakrabarti et al., 2010). Western blot analyses using anti-MOR and anti-KOR antibodies were performed using standard procedures as reported previously (Chakrabarti et al., 2010). The antiMOR antibody used was generated against the C-terminal 50 aa of MOR (Chalecka-Franaszek et al., 2000) (generously provided by Thomas Cote, Uniformed Services, University of the Health Sciences, Bethesda, MD). In contrast to the $\mathrm{N}$-terminally directed anti-KOR antibody used for KOR IP, the anti-KOR antibody that was used for KOR Western blot analysis was generated against amino acids 262-275 of KOR (Pierce). Because we had previously demonstrated the specificity of the MOR and KOR Western blot signals (Chakrabarti et al., 2010), these controls were not repeated in the present study.

Immunocytochemistry. Proestrus female rats were deeply anesthetized with a mixture of ketamine $(68 \mathrm{mg} / \mathrm{kg})$, xylazine $(4.6 \mathrm{mg} / \mathrm{kg})$, and acepromazine $(0.9 \mathrm{mg} / \mathrm{kg})$ and perfused through the ascending aorta with $100 \mathrm{ml}$ of ice-cold oxygenated calcium-free Tyrode's buffer $(115 \mathrm{~mm}$ $\mathrm{NaCl}, 5 \mathrm{~mm} \mathrm{KCl}, 2 \mathrm{~mm} \mathrm{MgCl}_{2} \cdot 6 \mathrm{H}_{2} \mathrm{O}, 400 \mu \mathrm{MgSO}_{4} \cdot \mathrm{H}_{2} \mathrm{O}, 3 \mathrm{~mm}$ glucose, and $25 \mathrm{~mm} \mathrm{NaHCO}_{3}, \mathrm{pH} 7.2$ ), followed by $500 \mathrm{ml}$ of freshly prepared buffered formaldehyde ( $4 \% \mathrm{w} / \mathrm{v}$ formaldehyde, $14 \% \mathrm{v} / \mathrm{v}$ saturated aqueous picric acid, $75 \mathrm{~mm} \mathrm{KH} \mathrm{PO}_{4}$, and $85 \mathrm{~mm} \mathrm{Na}_{2} \mathrm{HPO}_{4} \cdot 7 \mathrm{H}_{2} \mathrm{O}$, pH 6.9). After fixation, the entire vertebral column, including the pelvis, was harvested, placed in cryoprotectant solution $(15 \mathrm{~mm}$ sucrose, $30 \mathrm{~mm}$ $\mathrm{K}_{2} \mathrm{HPO}_{4}$, and $70 \mathrm{~mm} \mathrm{Na}_{2} \mathrm{HPO}_{4} \cdot \mathrm{H}_{2} \mathrm{O}, \mathrm{pH}$ 7.2), and shipped to Minnesota via overnight air courier service.

Tissue was quickly frozen, and serial sections were cut to a nominal thickness of $5 \mu \mathrm{m}$ on a cryostat (Bright Instruments), thawed onto Probe-On Plus microscope slides (Thermo Fisher Scientific), and stored at $-20^{\circ} \mathrm{C}$ until used. Sections were rinsed in distilled water, immersed in citrate buffer ( $10 \mathrm{~mm}$ trisodium citrate adjusted to $\mathrm{pH} 6.0)$ containing $0.05 \%$ Tween 20 , and autoclaved at $101^{\circ} \mathrm{C}$ for $30 \mathrm{~min}$. The sections were allowed to cool to room temperature, rinsed in TBS ( $135 \mathrm{~mm} \mathrm{NaCl}$ and $25 \mathrm{~mm}$ Tris- $\mathrm{HCl}, \mathrm{pH}$ 7.4), and then incubated in permeabilization solution (TBS containing $0.2 \%$ Triton X-100 and $0.2 \%$ Tween 20 ) for $1 \mathrm{~h}$ at room temperature. The sections were incubated with a 1:5000 dilution of guinea pig anti-MOR (raised against amino acids 384-398 of MOR, staining for which is not observed in MOR knock-out mice; generous gift from Dr. Robert Elde, University of Minnesota, Minneapolis , MN) and 1:1000 rabbit anti-KOR (KT2; gift from Charles Chavkin, University of Washington), 1:5000 rabbit anti-ER $\alpha$ [sc-542, aka MC-20; Santa Cruz 
Biotechnology; the staining specificity of which has been validated previously by confirming immunohistochemical results with a second anti-ER $\alpha$ antibody generated against a different epitope (Shim et al., 1999) and by preadsorbtion (Zeps et al., 1998)], or 1:3000 rabbit anti-GPR30 (LS-A4272; Lifespan Biosciences). Antibody dilutions were made in blocking buffer (TBS containing $0.1 \%$ Tween 20 and $0.2 \%$ casein); specificity of the primary antibodies was tested and confirmed using absorption controls and Western blots. The sections were washed with two changes of TBS and once with permeabilization solution over $1 \mathrm{~h}$ at room temperature. The sections were incubated for $2 \mathrm{~h}$ at room temperature in blocking buffer containing a mixture of $3 \mu \mathrm{g} / \mathrm{ml}$ each of donkey anti-rabbit IgG conjugated to Cy3 (Jackson ImmunoResearch) and donkey anti-guinea pig IgG conjugated to Cy2. The sections were washed in three changes of TBS, rinsed in distilled $\mathrm{H}_{2} \mathrm{O}$, dehydrated in increasing concentrations of ethanol (50-100\%), and cleared in xylene. The slides were mounted with coverslips using DPX Mountant (Fluka).

Microscopy. Images of labeling were collected using an Olympus Fluoview 1000 confocal microscope equipped with excitation at $488 \mathrm{~nm}(\mathrm{Cy} 2)$ and $543 \mathrm{~nm}$ (Cy3). Images were collected with $40 \times, 1.3$ numerical aperture or $60 \times, 1.4$ numerical aperture objectives and pixel dimensions of $0.32 \mu \mathrm{m}$ or smaller; all images were made using sequential scanning to avoid bleed-through. Although tissue was stained such that MOR-immunoreactivity (MOR-IR) was green and other labels were red (to take advantage of the brightness of Cy3), images were pseudocolored with MOR-IR red and other labels green, to enhance the visibility of double labeling.

Statistical analyses. One-way ANOVA was used to compare overall treatment effects on TFL among experimental groups. Paired analysis using Student's $t$ test was used to compare the treatment effect on spinal cord expression levels of KOR/MOR within each group.

\section{Results}

\section{Rapid signaling of spinal membrane ERs is essential for the} female-specific KOR-dependent spinal morphine antinociception

One-way ANOVA revealed a significant difference of treatment effects among different treatment groups (for various treatments, see Fig. 1) $\left(F_{(7,29)}=11.26 ; p<0.0001\right)$. Predictably, spinal morphine produced a robust antinociception $(78 \pm 7 \% \mathrm{MPE} ; p<$ $0.001, n=8$; TFL, 4.23 vs 8.71 ) (Fig. 1 ); peak effects occurred 30-40 min after intrathecal treatment. As reported previously (Liu et al., 2007), the antinociceptive effect was abolished by previous overnight intrathecal treatment with nor-BNI (26 nmol) (Fig. $1 A$ ) (TFL, 4.02 vs $4.71 ; p>0.05, n=10$ ). However, the intrathecal application of the $\operatorname{ER} \alpha$ and $\operatorname{ER} \beta$ antagonist (ICI 182,$780 ; 10 \mathrm{nmol} ; 30 \mathrm{~min}$ ) eliminated the blocking effect of norBNI on morphine antinociception (Fig. 1A); despite the overnight treatment with nor-BNI, spinal morphine produced an antinociception $(63 \pm 10 \% \mathrm{MPE}$; TFL, 4.28 vs 7.88 ; $p<0.001$, $n=11$ ) (Fig. $1 A$ ) that did not differ from that elicited by morphine in the absence of nor-BNI treatment $(p>0.05 ; \approx 81 \%$ of normative responsiveness to morphine). Notably, effects of ICI 182,780 were manifest as early as 15 min after its spinal administration (the earliest time point determined), at which time analgesic responses to morphine were $\sim 60 \%$ of control values.

Blockade of either ER $\alpha$ or ER $\beta$ was as rapid and effective (Fig. $1 B)$ as blockade of both receptors with ICI 182,780. In nor-BNI-
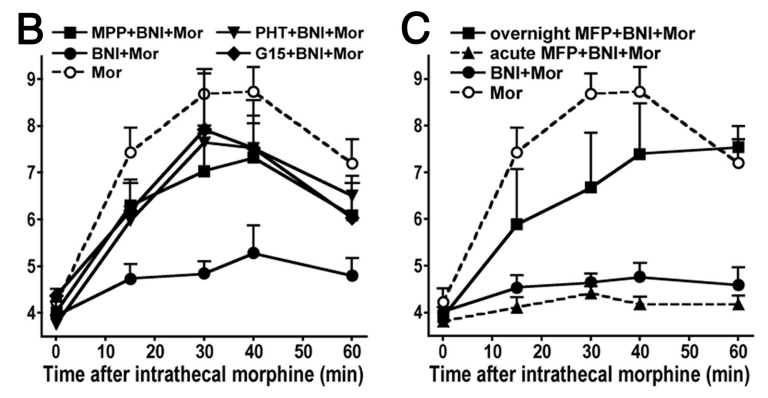

Time after intrathecal morphine ( $\mathrm{min})$

Figure 1. The KOR-dependent spinal morphine antinociception in proestrus rats requires rapid ER signaling as well as transcriptional effects of PR. ER antagonists were administered together with morphine $(5 \mu \mathrm{g})$ to the intrathecal space of proestrus rats that had been pretreated with intrathecal nor-BNI (BNl; $26 \mathrm{nmol}$ ) overnight. TFL was determined at various intervals thereafter. ffects of ER blockade could be observed as early as 15 min after antagonist administration. Data are shown as mean \pm SEM. $\boldsymbol{A}_{t}$ hecal application of ICl 182,780 (ICl; ER $\alpha$ and ER $\beta$ antagonist) concomitant with morphine (MOR) abrogated the inhibitory

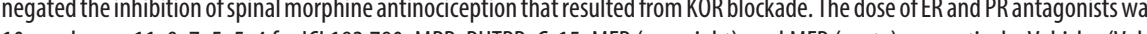
used to administer the antagonists did not alter the effect of nor-BNI on spinal morphine antinociception. None of the ER or PR

pretreated animals, intrathecal application of morphine and either $10 \mathrm{nmol}$ MPP (ER $\alpha$-selective antagonist $)$ or $10 \mathrm{nmol}$ PHTPP $(\mathrm{ER} \beta$-selective blocker) resulted in an antinociception that was $53 \pm 11 \%$ MPE (TFL, 4.03 vs 7.18; $p<0.05, n=9$ ) and $61 \pm 7 \%$ MPE (TFL, 3.77 to $7.59 ; p<0.05, n=7$ ), respectively, which did not differ from the magnitude of morphine antinociception elicited in the absence of nor-BNI pretreatment $(p>0.05)$. In addition, spinal G-15 (10 nmol), a highly selective antagonist of GPR30, also negated the effects of nor-BNI on the antinociceptive effects of spinal morphine (Fig. $1 B$ ). As was observed for ICI 182,780, MPP, and PHTPP, effects were observed by 15 min after intrathecal administration (the first time point established), at which time analgesic responses to morphine were $~ 50 \%$ of control values. By 30 min after intrathecal G-15, spinal morphine produced an antinociception ( $60 \pm 15 \% \mathrm{MPE}$; TFL, 4.37 vs 7.72 $p<0.05, n=7)$ that reflected the abolition of inhibitory effects of nor-BNI, i.e., the magnitude of the antinociception was indistinguishable from the antinociception produced by morphine in the absence of any nor-BNI treatment $(p>0.05)$.

Neither the overnight treatment with nor-BNI, the various ER antagonists, nor the vehicles (water, saline, or DMSO) used to administer drugs altered the basal TFL. Additionally, neither the ER blockers nor the vehicles used to administer them (water, saline, or DMSO) altered spinal morphine antinociception. The ability of acute ER blockade to reinstate normative spinal morphine antinociceptive responsiveness after KOR blockade underscores the fluidity and interrelatedness of the spinal morphine-activated antinociceptive pathways.

\section{The KOR dependency of spinal morphine antinociception also requires transcriptional activity of spinal PR}

Acute (up to $5 \mathrm{~h}$ ) intrathecal treatment with the PR blocker mifepristone $(10 \mathrm{nmol})$ failed to restore the morphine antinociception that was eliminated by nor-BNI ( $p>0.05$; TFL, 3.82 vs 4.29 ) (Fig. 1C). However, $16-18 \mathrm{~h}$ after intrathecal mifepristone, analgesic responsiveness to spinal morphine was significantly restored such that $5 \mu \mathrm{g}$ of spinal morphine now produced $51 \pm$ 13\% MPE (TFL, 3.91 vs $7.04 ; p<0.05, n=5$ ) (Fig. $1 C$ ). The temporal profile of the effects of intrathecal mifepristone suggests 
A

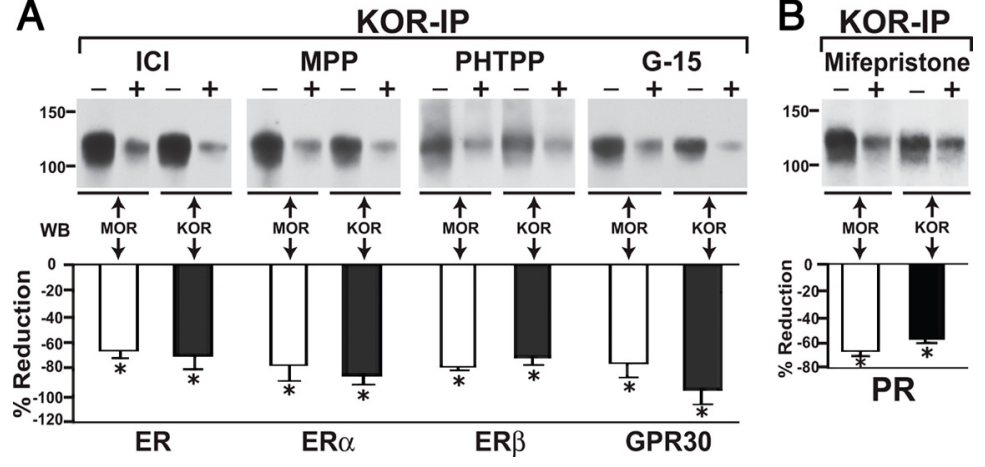

Figure 2. ER or PR blockade reduces KOR/MOR formation. A, Top, Immunoprecipitates obtained using anti-KOR antibodies from spinal cord of proestrus rats $30 \mathrm{~min}$ after intrathecal treatment with either vehicle or ICI 182,780 (ICI), MPP, PHTPP, or G-15 (10 nmol each) were Western blotted using anti-MOR antibodies and anti-KOR antibodies. An N-terminally directed anti-KOR antibody was used for IP, whereas the anti-KOR antibody used for Western blot analysis was generated against amino acids 262-275. The $\approx 120 \mathrm{kDa}$ KOR/MOR signal was always detected by anti-MOR and anti-KOR antibodies. Blockade of $\mathrm{ER} \alpha$, $\mathrm{ER} \beta$, or GPR30 markedly reduced $(\sim 70-80 \% ; p<0.05)$ spinal cord levels of KOR/MOR $(n=3-5)$. $\boldsymbol{B}$, Immunoprecipitates obtained using anti-KOR antibodies from spinal cord of proestrus rats that had been pretreated overnight with intrathecal vehicle or mifepristone ( $10 \mathrm{nmol})$ were Western blotted (WB) using anti-MOR or anti-KOR antibodies. A striking reduction $(\approx 62 \%)$ of the KOR/MOR Western blot signal was observed in mifepristone-pretreated rats versus no treatment using either antibody $(n=3)$. Bar graphs below Westerns blots in $\boldsymbol{A}$ and $\boldsymbol{B}$ shows percentage reduction (mean \pm SEM) of KOR/MOR expression produced by blocking individual ERs or PR ascertained by Western blot analyses using anti-MOR antibodies (open bars) or anti-KOR antibodies (filled bars). In accordance with the behavioral data shown in Figure 1, rapid signaling of membrane ERs but transcriptional effects of PR signaling are both essential for elevated expression of KOR/MOR during proestrus. Notably, ER and PR antagonists produced similar reductions in KOR/MOR expression. ${ }^{*} p<0.05$ for KOR/MOR expression in antagonist-treated versus untreated spinal cord that was analyzed in parallel.

the need for transcriptional (genomic) effects of PR (Labombarda et al., 2000, 2003).

\section{Acute spinal ER blockade substantially reduces KOR/MOR}

We previously demonstrated that KOR/MOR mediate the norBNI-sensitive (KOR-dependent), spinal morphine antinociception during proestrus (Chakrabarti et al., 2010). To directly assess the dependence of spinal KOR/MOR formation on ER activity, we quantified KOR/MOR in the absence versus the presence of acute (30 min) spinal ER blockade (Fig. 2A). Western blot analysis, using anti-MOR antibodies (MOR Western blot), of immunoprecipitate obtained using anti-KOR antibodies (KOR-IP) revealed that the spinal administration of the ER $\alpha / E R \beta$ blocker ICI 182,780 resulted in a $65.7 \pm 6 \%$ reduction in levels of $\mathrm{KOR} / \mathrm{MOR}(p<0.01, n=5)$. Analogous results were obtained using anti-KOR antibodies in Western blot analyses (KOR Western blot), of the same sample, run in parallel, which revealed a reduction in KOR/MOR levels of $69.4 \pm$ $10 \%(p<0.05, n=5)$. Similarly, MOR Western blot analyses of KOR-IP obtained from proestrus spinal tissue after the individual blockade of either spinal ER $\alpha$ (by MPP) or ER $\beta$ (by PHTPP) revealed reductions of $76.3 \pm 12 \%$ and $77.7 \pm 3 \%$, respectively $(p<$ $0.05, n=3$ for both blockers). Again, KOR Western blots of the same preparations yielded quantitatively comparable results ( $84.1 \pm 7$ and $70.3 \pm 6 \%$, respectively; $p<0.05$ for both blockers). Last, blockade of GPR30 via G-15 also reduced levels of KOR/MOR (MOR Western blot analysis, $75.3 \pm 10 \%$; KOR Western blot analysis, $80.9 \pm 11 \%$; $p<0.05, n=3$ for both) comparable with that produced by ER $\alpha$ or $\mathrm{ER} \beta$ blockade. There were no differences in spinal expression levels of KOR/MOR between vehicle-treated and untreated proestrus rats. These results indicate that activity of multiple types of spinal ER is a prerequisite for the enhanced formation of spinal KOR/MOR during proestrus. The concomitant diminution of (the enhanced) spinal KOR/MOR expression and the loss of nor-BNI inhibition of spinal morphine antinociception after blockade of ER underscore their causal association. These results also reveal the exchangeability of the
KOR (KOR/MOR)-dependent and KORindependent opioid analgesic mechanisms.

\section{KOR/MOR formation requires transcriptional activity of PR}

To directly assess the dependence of spinal KOR/MOR formation on PR activity, we quantified spinal KOR/MOR in the absence of and after an overnight intrathecal treatment with the same dose of mifepristone used in behavioral studies (Fig. 2B). Quantitatively similar findings were revealed by KOR and MOR Western blot analyses of the same sets of samples. Sustained PR blockade reduced KOR/MOR expression levels by $66 \pm 4.9 \%$ (MOR Western blot) and $58 \pm$ $3.7 \%$ (KOR Western blot) $(p<0.05$ for both, $n=3)$.

\section{Coincident activation of spinal ER $\alpha$, $E R \beta$, and GPR30 is required for the KOR-dependent spinal morphine antinociception and augmented KOR/ MOR formation}

Two types of organization of spinal ERs could account for the requirement that multiple types of spinal ERs be active for the manifestation of enhanced KOR/ MOR formation during proestrus: (1) ER $\alpha, \mathrm{ER} \beta$, and GPR30 could comprise an interactive macromolecular signaling complex and/or their respective signaling pathways could converge, and (2) ER $\alpha, E R \beta$, and GPR30 could comprise separate but parallel systems, each contributing a portion of the required ER activity. To differentiate between these possibilities, we determined whether the effect of combinations of a submaximal dose of ER blockers was additive. Strikingly, in proestrus rats that had been pretreated overnight with nor-BNI, the magnitude of spinal morphine antinociception observed after concomitant intrathecal treatment with 1 pmol of MPP and 10 pmol of G-15 (Fig. 3A) $(33.2 \pm 6 \% \mathrm{MPE} ; p<0.05, n=5)$ did not differ $(p>0.05)$ from that produced by intrathecal morphine and either 1 pmol of MPP $(40 \pm 6.5 \%$ MPE; $p<0.01, n=5)$ or 10 pmol of G-15 (38.8 \pm $6.6 \%$ MPE; $p<0.05, n=5$ ). Similarly, in nor-BNI pretreated proestrus rats, the antinociception produced by morphine after the combined intrathecal application of 1 pmol of MPP and 15 pmol of PHTPP (Fig. $3 B)(40.5 \pm 6 \%$ MPE; $p<0.05, n=6)$ did not significantly differ $(p>0.05)$ (Fig. $3 B$ ) from that produced by morphine after the individual intrathecal administration of MPP or PHTPP (data for $1 \mathrm{pmol}$ of MPP shown above; $15 \mathrm{pmol}$ of PHTPP, $33.5 \pm 4.6 \%$ MPE; $p<0.01, n=5$ ). Thus, blocking each ER type individually produced behavioral effects comparable with their concomitant antagonism.

We determined the effects on KOR/MOR expression levels during proestrus of the same low doses of ER blockers, alone and in combination (Fig. $3 C, D$ ), as were used in the behavioral studies shown above. Intrathecal MPP (1 pmol) reduced dimer formation by $38 \pm 6 \%$ and $36 \pm 6 \%$ as assessed by MOR and KOR Western blot analyses, respectively $(p<0.05, n=3)$. Intrathecal G-15 (10 pmol) reduced dimer formation by $52 \pm 2 \%$ and $49 \pm$ $5 \%$ as assessed by MOR and KOR Westerns blots, respectively $(p<0.05, n=3)$. This notwithstanding, treatment with a combination of 1 pmol of MPP and 10 pmol of G-15 reduced dimer formation by only $56 \pm 3 \%(p<0.05, n=3)$ (Fig. $3 C)$. In 

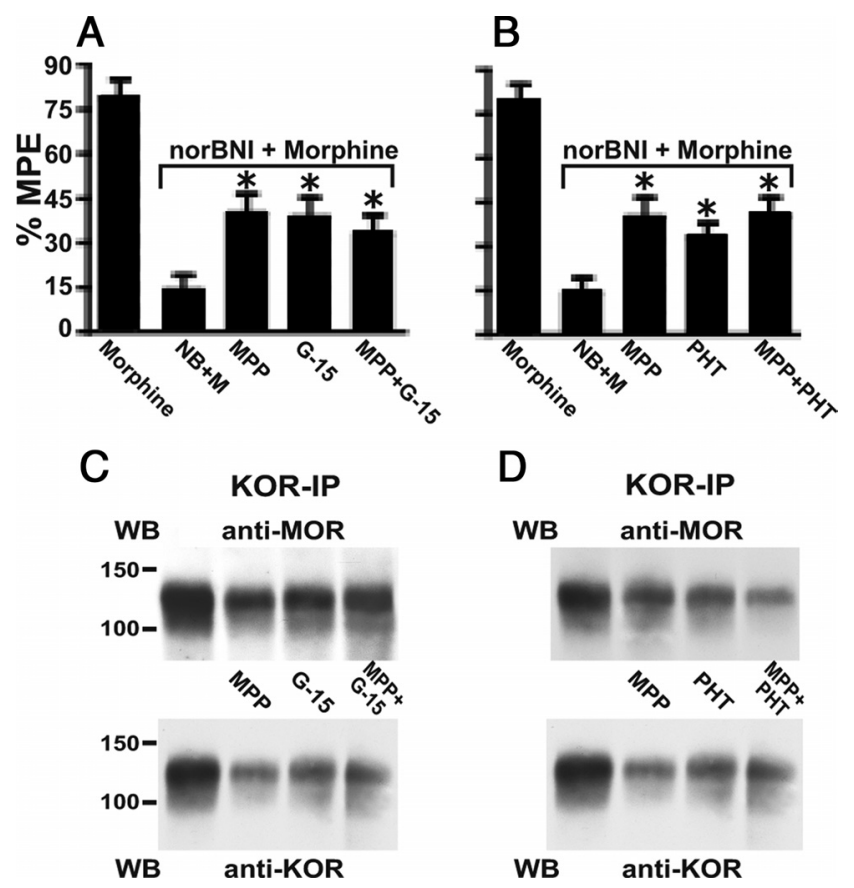

Figure 3. Concurrent but not additive activities of $\operatorname{ER} \alpha$, $E R \beta$, and GPR30 are required for the female-specific KOR-dependent spinal morphine antinociception and elevated spinal levels of heterodimeric KOR/MOR during proestrus. $A, B$, Intrathecal morphine $(5 \mu \mathrm{g})$ was administered together with 1 pmol of MPP, 10 pmol of G-15, 15 pmol of PHTPP (PHT) or combinations thereof (MPP + G-15; MPP + PHTPP) to proestrus rats that had been pretreated overnight with intrathecal nor-BNI (26 nmol). TFL was determined 30 min after morphine treatment. Data show peak effect of drugs expressed as \%MPE. C, D, Membranes obtained from spinal cord of proestrus rats that had been intrathecally treated for $30 \mathrm{~min}$ with vehicle (DMSO), one of two ER-type-selective blockers, or concomitantly with both were immunoprecipitated using anti-KOR antibodies. Immunoprecipitates were processed and Western blotted (WB) for KOR/MOR in parallel using anti-MOR and anti-KOR antibodies. Individual blockade of $E R \alpha, E R \beta$, or GPR30 partially restored spinal morphine antinociception despite nor-BNI pretreatment and partially reduced the levels of heterodimeric KOR/MOR. However, effects of MPP + G-15 or MPP + PHTPP on both measures were not significantly different from that which resulted from their individual application. ${ }^{*} p<0.05$ for comparison between antinociception resulting from morphine + nor-BNI versus morphine + nor-BNI + ER type-selective antagonists. NB, nor-BNI; M, morphine.

analogous manner, the combined intrathecal treatment with 1 pmol of MPP and 15 pmol of PHTPP reduced KOR/MOR expression levels by $55 \pm 6 \%$ and $63 \pm 2 \%$ in MOR and KOR Westerns blots, respectively (Fig. 3D), which did not differ from the reduction that resulted from their individual treatment (MPP, $45 \pm 8 \%$; PHTPP, $45 \pm 7 \%$ in MOR Western blots; and MPP, $55 \pm 7 \%$; PHTPP, $50 \pm 10 \%$ in KOR Westerns blots).

\section{Coexpression of MOR, KOR, ER $\alpha$, and GPR30}

The most parsimonious explanation for the findings presented above is that MOR, KOR, and multiple types of ER are coexpressed, which enables E2 to act directly on those neurons to enhance KOR/MOR formation. We tested these hypotheses using immunohistochemical analysis of tissue obtained from the L5 and L6 segments of proestrus rats. Double labeling was performed for MOR and the other receptors studied.

MOR-IR was found in the plasma membrane, within cell cytoplasm, and in fibrous cell processes. MOR-IR was densest in the inner portion of the superficial dorsal horn but was also found in the outer portion of the substantia gelatinosa, the marginal zone, the lateral reticulated area of the dorsal horn, and in the intermediate gray (Arvidsson et al., 1995a).
KOR-IR was very common in the superficial dorsal horn, as described previously by our group and others (Arvidsson et al., 1995b). Although it was most common in the marginal zone and the outer portion of the substantia gelatinosa, it extended into the inner portion of substantia gelatinosa as well and was sometimes expressed by MOR-IR neurons (Fig. 4G,H). In those cases, KOR-IR was found both within the cell cytoplasm and in or near the plasma membrane (Fig. 4G,H). KOR-IR and MOR-IR were sometimes also expressed in fibrous processes that may have been axons or small dendrites (Fig. $4 I--K$ ). In an arbitrarily selected section of dorsal horn measuring about $300 \times 300 \mu \mathrm{m}$, a total of $11 \mathrm{KOR}-\mathrm{IR}$ cell profiles were counted. A total of $10 \mathrm{MOR}-\mathrm{IR}$ cell profiles were counted in the same region. Of these, all the MOR-IR profiles also expressed KOR-IR. Of the 11 KOR-IR profiles, all but one also expressed MOR.

As we have observed previously (Gintzler et al., 2008), ER $\alpha$-IR cells were common in the superficial dorsal horn in the lumbosacral spinal cord. Density was lower in the lateral reticulated area and lower yet in nucleus proprius. However, labeling was also observed in the ventral horn and intermediate gray matter and was very prominent dorsal to the central canal, having a density similar to that in the superficial dorsal horn.

ER $\alpha$-IR was most frequently found in cell cytoplasm and nuclei. In addition, it occasionally was observed in cell processes and in the plasma membrane (Fig. 4A,B). Among MOR-IR neurons in proestrus female rats, coexpression of $\operatorname{ER} \alpha$-IR was very common. In an arbitrarily selected section of dorsal horn, a total of eight MOR-IR cell profiles and $36 \mathrm{ER} \alpha$-IR cell profiles were observed. Of these, six were double labeled for MOR and $\operatorname{ER} \alpha$ (i.e., $75 \%$ of MOR-IR profiles and $17 \%$ of ER $\alpha$-IR profiles were double labeled). Similarly, in the montage shown in Figure 4A, 10 of 11 MOR-IR profiles were double labeled for ER $\alpha$-IR.

The distribution of GPR30-IR was similar to that of $\mathrm{ER} \alpha$, being most prominent in the superficial dorsal horn and in the region dorsal and adjacent to the central canal. Labeling was also observed in other parts of the dorsal horn, intermediate gray, and occasionally in motor neurons in the ventral horn. GPR30-IR was less dense than that for $\mathrm{ER} \alpha$ and consisted of small puncta found within the cell cytoplasm and plasma membrane (Fig. 4D).

GPR30-IR was sometimes expressed by MOR-IR neurons, both in the cytoplasm and in or near the plasma membrane (Fig. $4 D, E)$. In some of those cases, GPR30 appeared to overlay perfectly with MOR-IR structures (Fig. $4 D, E$ ). In an arbitrarily selected section, eight MOR-IR profiles were identified, and, of these, three also expressed GPR30.

Because three of the four antibodies that we used were raised in rabbits, we could only stain for combinations of MOR-IR with one of the other antigens. However, by examining serially adjacent $5 \mu \mathrm{m}$ sections, we could occasionally track a single cell through multiple sections and characterize it more extensively. Using this method, we found that MOR-IR, KOR-IR, ER $\alpha$-IR, and GPR30-IR were sometimes all coexpressed in the same cell (Fig. 5).

\section{Spinal cord aromatase activity is essential for the female-} specific KOR-dependent spinal morphine antinociception To determine whether local production of E2 is essential for the KOR-dependent spinal morphine antinociception, we determined the effect of inhibiting spinal cord aromatase activity on the nor-BNI inhibition of spinal morphine antinociception (Fig. 6). Fadrozole (FAD; $2.5 \mathrm{nmol}$ ) administered concomitantly with morphine failed to negate the nor-BNI inhibition of morphine antinociception. However, a $1 \mathrm{~h}$ pretreatment with intrathecal fadrozole eliminated the dependence of spinal morphine antino- 

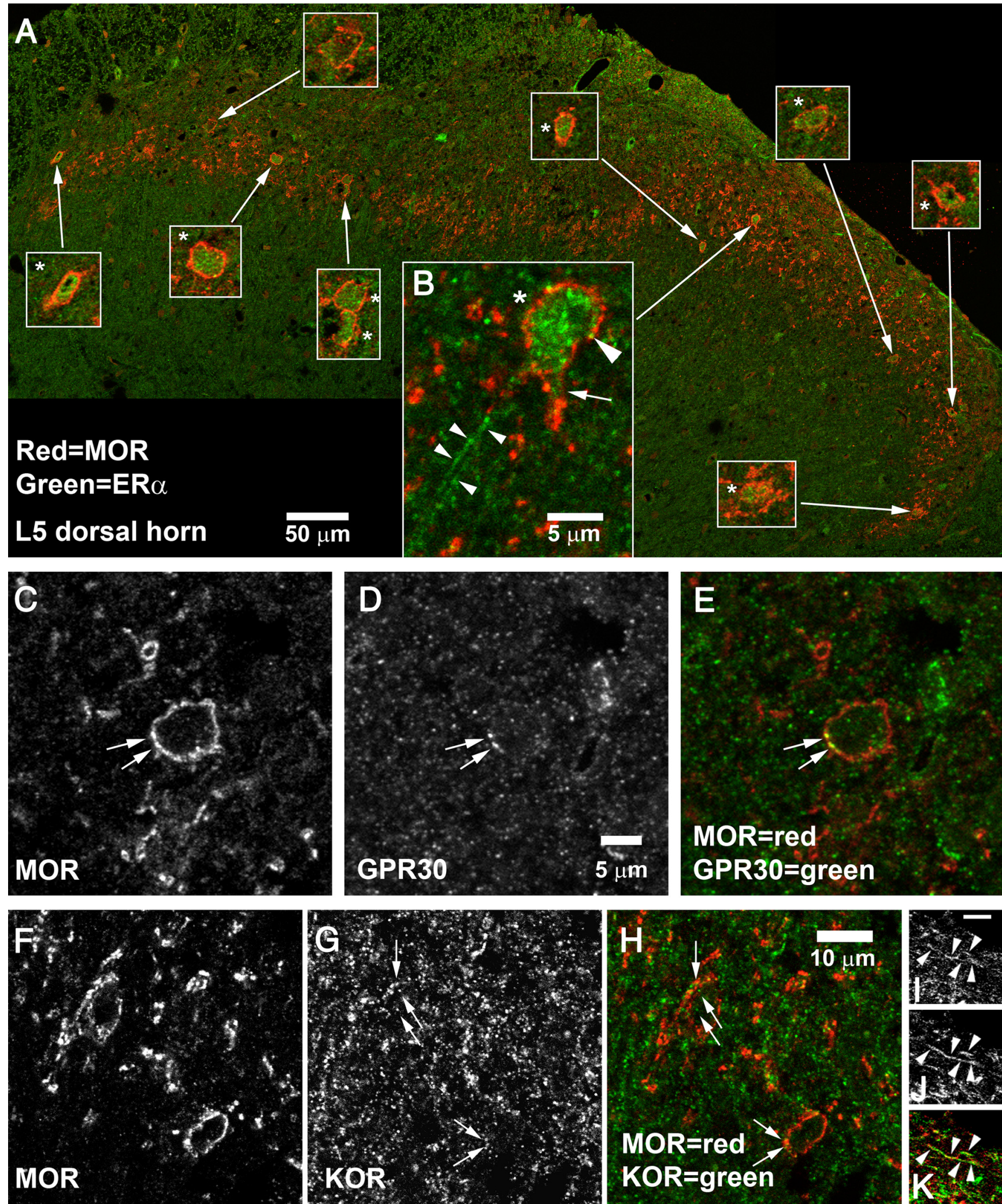

Figure 4. Coexpression of MOR-IR with $E R \alpha, G P R 30$, or KOR in the superficial dorsal horn. $A, B, M O R+E R \alpha$. $A, A$ montage of the entire superficial dorsal horn of a single section of $L 5$ spinal cord. Insets show $3 \times$ higher-magnification views of the cells pointed out by the arrows; cells labeled by ER $\alpha$ are marked with an asterisk (*). ER $\alpha$-IR was found in 9 of the 10 MOR-IR cells. $B$, High-magnification view of a cell in the central-lateral superficial dorsal horn. ER $\alpha-\operatorname{IR}$ was not restricted to the cell nucleus but also appeared to be in the plasma membrane (large arrowhead) and to extend into proximal dendrites (arrow). ER $\alpha$-IR was also present in fibrous processes (small arrowheads). The $50 \mu \mathrm{m}$ scale bar in $\boldsymbol{A}$ applies only to the large montage; magnification of insets is $3 \times$ higher. The $5 \mu \mathrm{m}$ scale bar in $\boldsymbol{B}$ applies only to $\boldsymbol{B}$. $\boldsymbol{C}-\boldsymbol{E}$, Expression of GPR30 by an MOR-IR cell in L6 superficial dorsal horn. Arrows mark MOR-GPR30 double labeling. GPR30-IR can also be seen within the cell cytoplasm. $\boldsymbol{F}-\boldsymbol{K}$, Coexpression of MOR-IR and KOR-IR. $\boldsymbol{F}-\boldsymbol{H}, \mathrm{MOR}-\mathrm{KOR}$ coexpression in somata. Arrows mark KOR-IR structures visible in MOR-IR neurons in L5 superficial dorsal horn. Double labeling frequently appeared to be in or near the plasma membrane, but sometimes was also seen in the cytoplasm. $\boldsymbol{I}-\boldsymbol{K}$, MOR-KOR coexpression in fibrous processes. Arrowheads mark a fiber in L5 superficial dorsal horn that was double labeled for MOR and KOR. Scale bar (in I): $\boldsymbol{I} \boldsymbol{K}$, is $2 \mu \mathrm{m}$. 

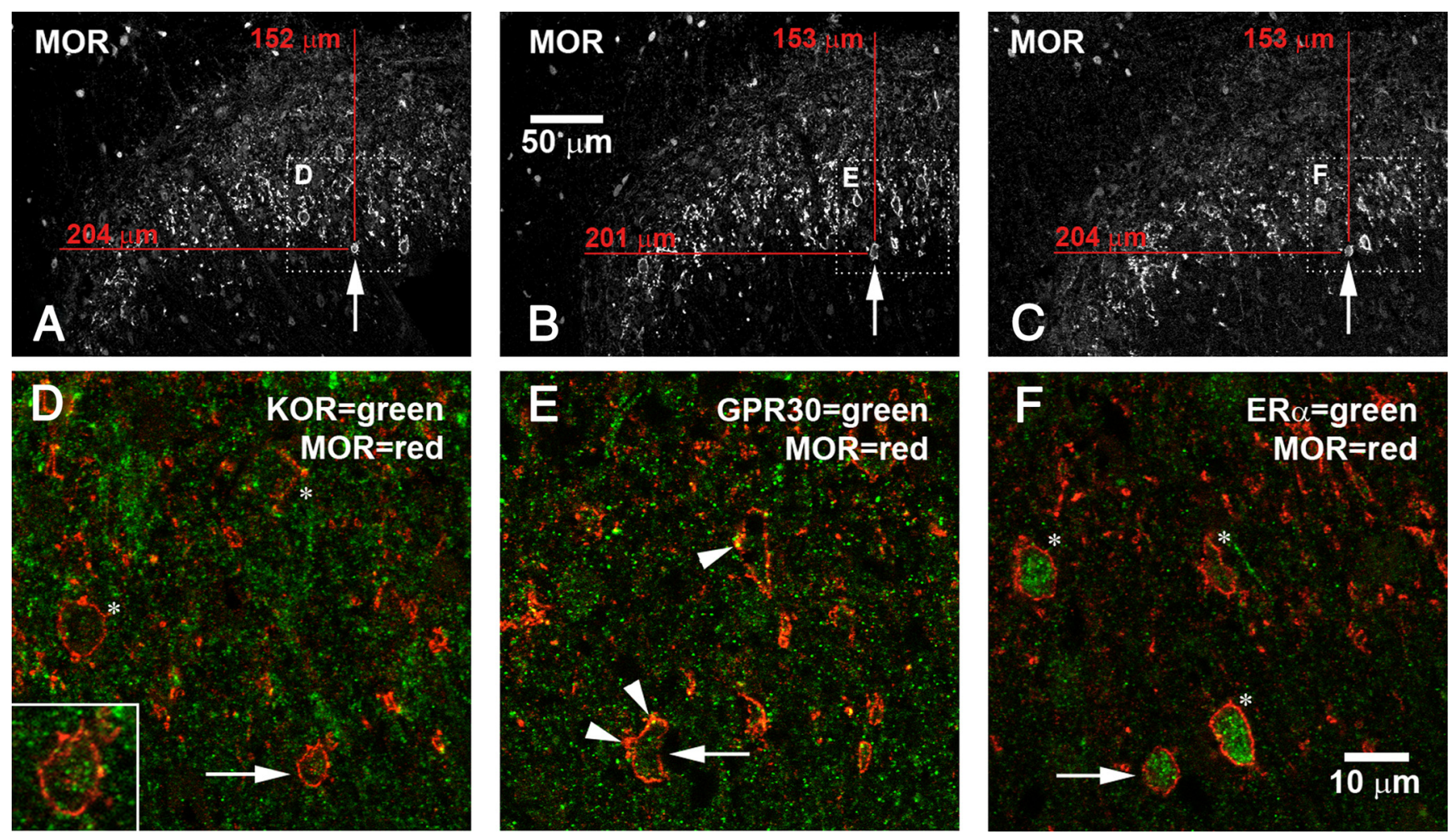

Figure 5. MOR, GPR30, ER $\alpha$, and KOR expressed in a single dorsal horn neuron. Confocal microscopic images are taken from three serially adjacent $5 \mu \mathrm{m}$ cryostat sections. $A-C$, Lowermagnification images that provide overviews of the region. Arrows point to a single cell visible in all three sections expressing all four receptors. Dotted boxes outline the regions shown in $\mathbf{D}-\boldsymbol{F}$. $\boldsymbol{D}-\boldsymbol{F}$, Higher-magnification images that show double labeling for MOR and KOR (D), MOR and GPR3O (E), or MOR and ER $\alpha(\boldsymbol{F})$. Again, arrows point to a single cell that expresses all four receptors. $\boldsymbol{D}$, Asterisks mark other MOR-IR cells that also express KOR-IR; inset shows a higher-magnification view of the cell marked by the arrow. Note green KOR-IR inside the MOR-IR cell. E, Arrowheads mark GPR30-IR in or near plasma membranes of MOR-IR neurons. (GPR30-IR is also visible inside the cytoplasm.) Note GPR30-IR in cell marked by arrow. $F$, Note ER $\alpha$-IR in the MOR-IR cell marked by the arrow. Most MOR-IR neurons also expressed ER $\alpha$ (asterisks).

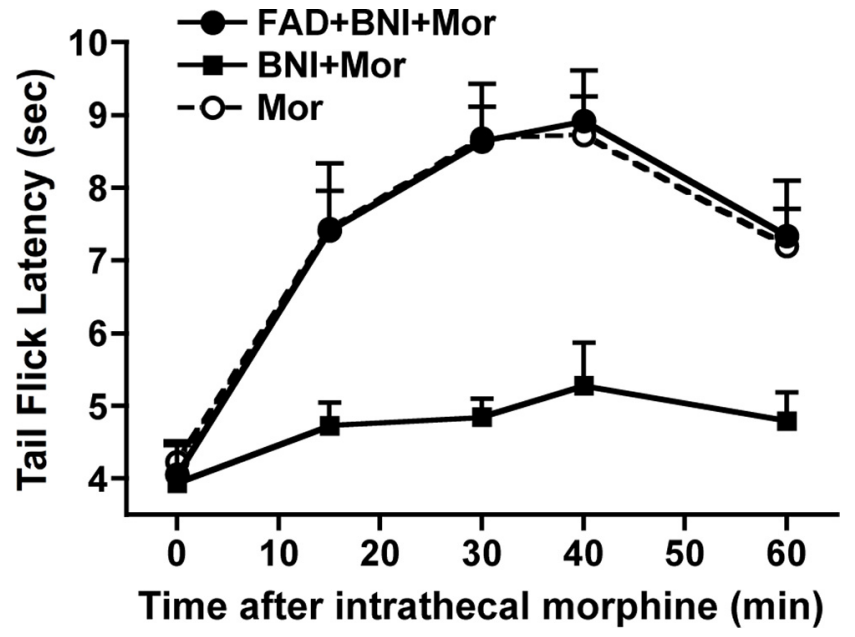

Figure 6. Inhibition of spinal cord aromatase eliminated the female-specific KORdependent spinal morphine (MOR) antinociception during proestrus. Fadrozole (FAD; $2.5 \mathrm{nmol}$ ) was administered to the intrathecal space of proestrus rats that had been pretreated overnight with nor-BNI (BNl; $26 \mathrm{nmol})$. One hour later, morphine $(5 \mu \mathrm{g})$ was given intrathecally. TFL determination commenced 30 min thereafter. Intrathecal fadrozole significantly restored the nor-BNI blocked morphine antinociception.

ciception on KOR, i.e., FAD fully restored the nor-BNI-blocked morphine antinociception $(80 \pm 10 \% \mathrm{MPE}$; TFL, 4.06 vs 8.78 ; $p<0.001, n=5$ and 7 for FAD + nor-BNI + morphine vs nor-BNI + morphine groups, respectively). In contrast, the same intrathecal dose of fadrozole had no effect when it was adminis- tered systemically (intramuscularly). This indicates that E2 synthesized in the spinal cord is a critical source of the E2 required for the emergence of the female-specific morphine-activated spinal KOR (KOR/MOR) analgesic mechanism during proestrus.

\section{Discussion}

This study demonstrates four salient findings: (1) concomitant activation of spinal cord ER and PR is a prerequisite for the previously demonstrated elevated expression of KOR/MOR and the manifestation of the KOR-dependent spinal morphine antinociception during proestrus; (2) effects of ER blockade are manifest within minutes (suggesting membrane-initiated signaling by E2), whereas effects of PR blockade require in excess of $5 \mathrm{~h}$ to be observed (suggesting that $\mathrm{P}_{4}$ acts via transcriptional activation); (3) concomitant but nonadditive activation of membrane $\mathrm{ER} \alpha, \mathrm{ER} \beta$, and GPR30 is essential; and (4) spinal cord synthesis of E2 is essential for the KORdependent spinal morphine antinociception during proestrus. These findings are integrated in the diagram depicted in Figure 7.

Rapid signaling of multiple types of ER contributes to KOR/ MOR formation and the female specific KOR-dependent spinal morphine antinociception

Intrathecal ICI 182,780, which antagonizes both $\mathrm{ER} \alpha$ and $\mathrm{ER} \beta$, eliminated the effect of previous treatment with intrathecal norBNI on spinal morphine antinociception, i.e., ICI 182,780 eliminated the dependence of spinal morphine antinociception on KOR. ICI 182,780 also reduced the spinal cord expression of KOR/MOR by $>70 \%$. This not only indicates the dependence on $\mathrm{E} 2$ of elevated KOR/MOR formation and the nor-BNI-sensitive 


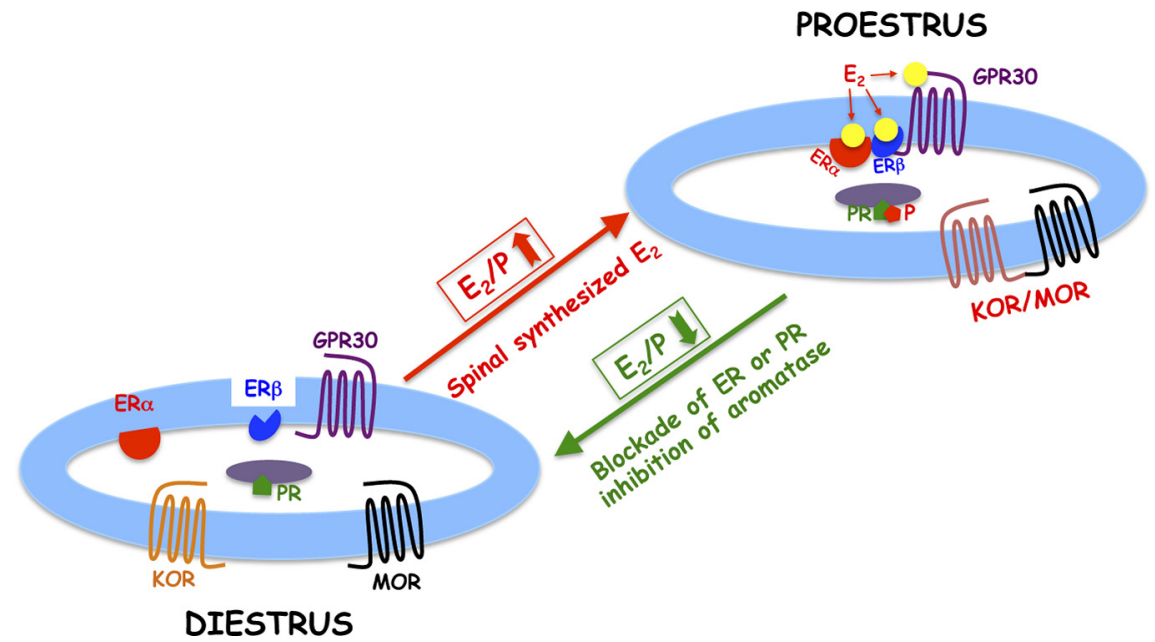

Figure 7. Schematic representation of the modulation of KOR/MOR formation by $E 2$ and $\mathrm{P}_{4} . M O R$, KOR, ER $\alpha$, and GPR30 are coexpressed in neurons of the spinal dorsal horn. Biochemical and behavioral experiments suggest that ERs work in a cooperative manner as part of a macromolecular complex to increase KOR/MOR expression. We hypothesize that E2 (spinally synthesized and ovarian derived) triggers the formation of a signaling complex that contains multiple ERs, which via as of yet unknown mechanism(s) enhances heterodimerization of KOR and MOR. Transcriptional effects of $\mathrm{P}_{4}$ are essential either for the formation of the ER signaling complex and/or the heterodimerization of KOR with MOR.

spinal morphine antinociception during proestrus but also supports their inferred causal association (Chakrabarti et al., 2010). Effects of ICI 182,780 are not likely to be mediated via antagonism of GPR30 because ICI 182,780 is an agonist at this receptor (Thomas et al., 2005).

Notably, we observed effects on KOR-dependent spinal morphine antinociception and KOR and MOR heterodimerization of G-15, MPP, and PHTPP at intrathecal doses as low as 10, 1, and 15 pmol, respectively, which would result in concentrations at ER of no more than 100, 10 , and $150 \mathrm{nM}$, respectively, assuming an intrathecal space of $100 \mu \mathrm{l}$. G-15 does not interact with either $\mathrm{ER} \alpha$ or $\mathrm{ER} \beta$ up to $10 \mu \mathrm{M}$. Ten nanomolar MPP and 150 nM PHTPP are 180-fold and 72-fold below their $K_{\mathrm{i}}$ for $\operatorname{ER} \alpha$ and $\operatorname{ER} \beta$, respectively. These considerations strongly suggest that activation of $\mathrm{ER} \alpha, \mathrm{ER} \beta$, and GPR30, individually, is essential to the enhanced formation of spinal KOR/MOR and the KOR-dependent spinal morphine antinociception during proestrus.

Strikingly, effects of all three antagonists were manifest by 15 min after their intrathecal application, at which time $\sim 50 \%$ of antinociceptive responsiveness to morphine was restored. Transcription of some immediate early genes convincingly occurs by 20 min (Lanaud et al., 1993). However, the observed onset of effects of blocking spinal ERs (within $15 \mathrm{~min}$ ) is faster than the appearance of the effects of immediate early gene transcription, which require trans gene activation and the synthesis of proteins. Furthermore, if ER antagonists were acting via transcription, the effect would be to block it, the physiological manifestation of which requires depletion of existing protein pools. This is not likely to occur within the $15 \mathrm{~min}$ in which effects of spinal ER blockade are observed. These considerations support the conclusion that plasma membrane-initiated signaling by ERs is critical to spinal KOR/MOR expression and KOR-dependent spinal morphine antinociception. The rapid onset of effects after ER blockade also underscores that $\mathrm{KOR} / \mathrm{MOR}$ signaling is very short lived.

\section{$\mathrm{ER} \boldsymbol{\alpha}, \mathrm{ER} \boldsymbol{\beta}$, and GPR30 work in tandem, but their contributions are not additive}

Acute antagonism of spinal $\mathrm{ER} \alpha, \mathrm{ER} \beta$, or GPR30, individually, produced similar reductions in spinal KOR/MOR $(\approx 75 \%)$. Analogous findings were observed regarding the restoration of spinal morphine antinociception $(\approx 75 \%)$ despite the continued presence of norBNI. Furthermore, the magnitude of the effects resulting from intrathecal treatment with MPP and G-15 or MPP and PHTPP were not statistically different from the reduction that ensued after their individual spinal application. The interdependence of $\mathrm{ER} \alpha, \mathrm{ER} \beta$, and GPR30 could indicate that they function in tandem as part of a macromolecular signaling complex to regulate $\mathrm{KOR} / \mathrm{MOR}$ formation.

In this regard, it should be noted that E2 stimulates the heterodimerization of $\mathrm{ER} \alpha$ and $\mathrm{ER} \beta$ (Razandi et al., 2004; Levin, 2008). There is also a growing consensus that GPR30 collaborates with membranelocalized ER $\alpha$ to effect signal transduction (Vivacqua et al., 2006; Albanito et al., 2007). Indeed, the specificity of signals generated by E2 is thought to depend, at least in part, on the cell contextdependent assembly of a "signalsome" comprising $>10$ signal molecules (Levin, 2008).

\section{Spinal localization of ERs}

Previous studies have shown that $\mathrm{ER} \alpha$ and to a lesser extent ER $\beta$ are present in neurons of the spinal cord dorsal horn (Papka et al., 2001; Gintzler et al., 2008) in areas that topographically correspond to the distribution of central processes of visceral primary afferent neurons (Papka et al., 2002; Vanderhorst et al., 2009). These areas also express opioid receptors, which localize to presynaptic terminals of primary sensory neurons as well as to their postsynaptic targets in laminae I and II (Kline and Wiley, 2008). In the present study, we found that MOR-IR neurons in the dorsal horn frequently expressed $\mathrm{ER} \alpha$. Additionally, GPR30 was coexpressed with $\mathrm{ER} \alpha$ in somata that were immunoreactive for both KOR and MOR. The colocalization of KOR, MOR, ER $\alpha$, and GPR30 within the superficial dorsal horn is not only consistent with the current demonstration that ERs work in cooperative manner to regulate KOR/MOR formation but provides a structural basis for the ability of sex steroids to regulate KOR/MOR formation and mechanisms harnessed by spinal morphine.

\section{In situ synthesis of $\mathrm{E} 2$ by spinal cord is critical for female-specific KOR (KOR/MOR)-dependent spinal morphine antinociception}

In addition to peripheral sources, E2 is also synthesized in situ by spinal tissue via aromatase. Aromatase is present in spinal cord laminae I and II and the region around the central canal (Evrard, 2006), areas known to be involved in nociception and opioid antinociception.

Inhibition of spinal aromatase (via fadrozole) fully restored the spinal morphine antinociception that had been eliminated by nor-BNI, indicating the importance of local spinal cord production of E2 to female phenotypic antinociceptive responsiveness to spinal morphine. The ability of aromatase inhibition to shift morphine-induced antinociceptive signaling from KOR (KOR/ MOR)-dependent to a KOR-independent mechanism indicates the ability of aromatase to act as a molecular switch to fine-tune KOR functionality. Previous studies have demonstrated that locally synthesized E2 can produce rapid alterations in nociceptive 
responsiveness (Evrard and Balthazart, 2004). Our current data indicate that alterations in KOR/MOR formation could underlie that effect.

Aromatase activity in the CNS is not fixed. It can be rapidly modulated (within minutes), e.g., by phosphorylation (Balthazart et al., 2001a,b). This could enable spinal aromatase activity to vary in parallel with circulating levels of E2. A surge of spinal cord aromatase activity during proestrus would result in a rapid, localized increase in spinal cord E2, which could be sufficient to achieve the increase in ER activity required for the heterodimerization of KOR with MOR. Alternatively, peripheral and spinal cord-derived E2 could act in concert whereby the elevated peripheral levels of E2 during proestrus are superimposed on existing steady-state levels of spinally produced E2 to achieve the requisite levels of spinal ER activity. Present data do not permit distinguishing between these possibilities.

\section{Functionality of spinal PRs}

Like ER, PRs function as a ligand-activated transcription factor to regulate expression of specific gene networks throughout the spinal cord (Labombarda et al., 2010 and references contained therein). Additionally, several plasma membrane-associated PRs transduce signaling cascades, thereby mediating rapid effects of $\mathrm{P}_{4}$ that are independent of transcription (Majewska et al., 1986; Labombarda et al., 2010). The requirement for an overnight spinal treatment with mifepristone for effects of PR blockade to be observed suggests that the transcriptional activity of $\mathrm{P}_{4}$, but not its ability to rapidly modulate plasma membrane signaling, is critical for both the female phenotypic (nor-BNI-sensitive) analgesic response to spinal morphine as well as elevated KOR/MOR expression levels during proestrus.

\section{Fluidity of KOR (KOR/MOR)-dependent and -independent spinal morphine signaling pathways}

The ability of ER or PR blockade to restore the component of spinal morphine antinociception that had been eliminated by spinal KOR blockade reveals the presence of parallel KORdependent and KOR-independent morphine-activated antinociceptive systems. The latter does not contribute to spinal morphine antinociception during proestrus but is activated by morphine when the ER- and PR-dependent KOR/MOR pathway is impaired, e.g., after ER or PR blockade or during diestrus, at which times intrathecal nor-BNI does not diminish spinal morphine antinociception (Chakrabarti et al., 2010). The exchangeability of the KOR-dependent and KOR-independent spinal analgesic mechanisms is underscored by the ability of intrathecal morphine to elicit comparable antinociception during diestrus and proestrus, with or without intrathecal treatment with norBNI and spinal ER or PR blockade. This reveals that available spinal analgesic mechanisms oscillate in accordance with physiological condition, e.g., stage of estrous cycle, between the proestrus-specific spinal KOR/MOR pathway and the MOR pathway that traditionally is thought to mediate spinal morphine antinociception (Liu et al., 2007; Chakrabarti et al., 2010).

We hypothesize that monomeric KOR mediates nociception, whereas KOR that heterodimerizes with MOR mediates antinociception. This formulation would explain the paradoxical findings that butorphanol and nalbuphine (mixed $\mu$-/ $\kappa$-opioid receptor ligands) are antinociceptive in women, whereas in men they produce nociception (Gear et al., 1996, 2000). Our formulation would also explain, at least in part, the recent report that spinal KOR-mediated attenuation of acute inflammatory pain in the rat is dependent on E2 (Lawson et al., 2010). As a corollary, we suggest that enhanced formation of KOR/MOR shifts the function of endogenous dynorphin from pronociceptive to antinociceptive. Stimulation by sex steroids of the formation of KOR/ MOR suggests that it could serve as a novel molecular target for the management of pain in women.

\section{References}

Albanito L, Madeo A, Lappano R, Vivacqua A, Rago V, Carpino A, Oprea TI, Prossnitz ER, Musti AM, Andò S, Maggiolini M (2007) G proteincoupled receptor 30 (GPR30) mediates gene expression changes and growth response to 17beta-estradiol and selective GPR30 ligand G-1 in ovarian cancer cells. Cancer Res 67:1859-1866.

Arvidsson U, Riedl M, Chakrabarti S, Lee JH, Nakano AH, Dado RJ, Loh HH, Law PY, Wessendorf MW, Elde R (1995a) Distribution and targeting of a $\mu$-opioid receptor (MOR1) in brain and spinal cord. J Neurosci 15:3328-3341.

Arvidsson U, Riedl M, Chakrabarti S, Vulchanova L, Lee JH, Nakano AH, Lin X, Loh HH, Law PY, Wessendorf MW, Elde R (1995b) The k-opioid receptor (KOR1) is primarily postsynaptic: combined immunohistochemical localization of the receptor and endogenous opioids. Proc Natl Acad Sci U S A 92:5062-5066.

Balthazart J, Baillien M, Ball GF (2001a) Rapid and reversible inhibition of brain aromatase activity. J Neuroendocrinol 13:63-73.

Balthazart J, Baillien M, Ball GF (2001b) Phosphorylation processes mediate rapid changes of brain aromatase activity. J Steroid Biochem Mol Biol 79:261-277.

Bonini JA, Anderson SM, Steiner DF (1997) Molecular cloning and tissue expression of a novel orphan $\mathrm{G}$ protein-coupled receptor from rat lung. Biochem Biophys Res Commun 234:190-193.

Carmeci C, Thompson DA, Ring HZ, Francke U, Weigel RJ (1997) Identification of a gene (GPR30) with homology to the G-protein-coupled receptor superfamily associated with estrogen receptor expression in breast cancer. Genomics 45:607-617.

Chakrabarti S, Liu NJ, Gintzler AR (2010) Formation of $\mu / \kappa$-opioid receptor heterodimer is sex-dependent and mediates female-specific opioid analgesia. Proc Natl Acad Sci U S A 107:20115-20119.

Chalecka-Franaszek E, Weems HB, Crowder AT, Cox BM, Côté TE (2000) Immunoprecipitation of high-affinity, guanine nucleotide-sensitive, solubilized mu-opioid receptors from rat brain: coimmunoprecipitation of the G proteins G(alpha o), G(alpha i1), and G(alpha i3). J Neurochem 74:1068-1078.

Couse JF, Korach KS (1999) Estrogen receptor null mice: what have we learned and where will they lead us? Endocr Rev 20:358-417.

Evrard HC (2006) Estrogen synthesis in the spinal dorsal horn: a new central mechanism for the hormonal regulation of pain. Am J Physiol Regul Integr Comp Physiol 291:R291-R299.

Evrard HC, Balthazart J (2004) Rapid regulation of pain by estrogens synthesized in spinal dorsal horn neurons. J Neurosci 24:7225-7229.

Feng Y, Gregor P (1997) Cloning of a novel member of the G proteincoupled receptor family related to peptide receptors. Biochem Biophys Res Commun 231:651-654.

Filardo EJ, Quinn JA, Bland KI, Frackelton AR Jr (2000) Estrogen-induced activation of Erk-1 and Erk-2 requires the G protein-coupled receptor homolog, GPR30, and occurs via trans-activation of the epidermal growth factor receptor through release of HB-EGF. Mol Endocrinol 14:1649-1660.

Filardo EJ, Quinn JA, Sabo E (2008) Association of the membrane estrogen receptor, GPR30, with breast tumor metastasis and transactivation of the epidermal growth factor receptor. Steroids 73:870-873.

Gear RW, Miaskowski C, Gordon NC, Paul SM, Heller PH, Levine JD (1996) Kappa-opioids produce significantly greater analgesia in women than in men. Nat Med 2:1248-1250.

Gear RW, Miaskowski C, Gordon NC, Paul SM, Heller PH, Levine JD (2000) Action of naloxone on gender-dependent analgesic and antianalgesic effects of nalbuphine in humans. J Pain 1:122-127.

Gintzler AR, Schnell SA, Gupta DS, Liu NJ, Wessendorf MW (2008) Relationship of spinal dynorphin neurons to delta-opioid receptors and estrogen receptor alpha: anatomical basis for ovarian sex steroid opioid antinociception. J Pharmacol Exp Ther 326:725-731.

Kline RH 4th, Wiley RG (2008) Spinal mu-opioid receptor-expressing dorsal horn neurons: role in nociception and morphine antinociception. J Neurosci 28:904-913. 
Labombarda F, Guennoun R, Gonzalez S, Roig P, Lima A, Schumacher M, De Nicola AF (2000) Immunocytochemical evidence for a progesterone receptor in neurons and glial cells of the rat spinal cord. Neurosci Lett 288:29-32.

Labombarda F, Gonzalez SL, Deniselle MC, Vinson GP, Schumacher M, De Nicola AF, Guennoun R (2003) Effects of injury and progesterone treatment on progesterone receptor and progesterone binding protein 25-Dx expression in the rat spinal cord. J Neurochem 87:902-913.

Labombarda F, Meffre D, Delespierre B, Krivokapic-Blondiaux S, Chastre A, Thomas P, Pang Y, Lydon JP, Gonzalez SL, De Nicola AF, Schumacher M, Guennoun R (2010) Membrane progesterone receptors localization in the mouse spinal cord. Neuroscience 166:94-106.

Lanaud P, Maggio R, Gale K, Grayson DR (1993) Temporal and spatial patterns of expression of $\mathrm{c}$-fos, zif/268, c-jun and jun-B mRNAs in rat brain following seizures evoked focally from the deep prepiriform cortex. Exp Neurol 119:20-31.

Lawson KP, Nag S, Thompson AD, Mokha SS (2010) Sex-specificity and estrogen-dependence of kappa opioid receptor-mediated antinociception and antihyperalgesia. Pain 151:806-815.

Leonhardt SA, Boonyaratanakornkit V, Edwards DP (2003) Progesterone receptor transcription and non-transcription signaling mechanisms. Steroids 68:761-770.

Levin ER (2008) Rapid signaling by steroid receptors. Am J Physiol Regul Integr Comp Physiol 295:R1425-R1430.

Levin ER (2009) G protein-coupled receptor 30: estrogen receptor or collaborator? Endocrinology 150:1563-1565.

Liu NJ, von Gizycki H, Gintzler AR (2007) Sexually dimorphic recruitment of spinal opioid analgesic pathways by the spinal application of morphine. J Pharmacol Exp Ther 322:654-660.

Majewska MD, Harrison NL, Schwartz RD, Barker JL, Paul SM (1986) Steroid hormone metabolites are barbiturate-like modulators of the GABA receptor. Science 232:1004-1007.

Mermelstein PG (2009) Membrane-localised oestrogen receptor alpha and beta influence neuronal activity through activation of metabotropic glutamate receptors. J Neuroendocrinol 21:257-262.

Micevych P, Dominguez R (2009) Membrane estradiol signaling in the brain. Front Neuroendocrinol 30:315-327.
Papka RE, Storey-Workley M, Shughrue PJ, Merchenthaler I, Collins JJ, Usip S, Saunders PT, Shupnik M (2001) Estrogen receptor-alpha and betaimmunoreactivity and mRNA in neurons of sensory and autonomic ganglia and spinal cord. Cell Tissue Res 304:193-214.

Papka RE, Hafemeister J, Puder BA, Usip S, Storey-Workley M (2002) Estrogen receptor-alpha and neural circuits to the spinal cord during pregnancy. J Neurosci Res 70:808-816.

Razandi M, Pedram A, Merchenthaler I, Greene GL, Levin ER (2004) Plasma membrane estrogen receptors exist and functions as dimers. Mol Endocrinol 18:2854-2865.

Revankar CM, Cimino DF, Sklar LA, Arterburn JB, Prossnitz ER (2005) A transmembrane intracellular estrogen receptor mediates rapid cell signaling. Science 307:1625-1630.

Shim WS, DiRenzo J, DeCaprio JA, Santen RJ, Brown M, Jeng MH (1999) Segregation of steroid receptor coactivator-1 from steroid receptors in mammary epithelium. Proc Natl Acad Sci U S A 96:208-213.

Takada Y, Kato C, Kondo S, Korenaga R, Ando J (1997) Cloning of cDNAs encoding $\mathrm{G}$ protein-coupled receptor expressed in human endothelial cells exposed to fluid shear stress. Biochem Biophys Res Commun 240:737-741.

Thomas P, Pang Y, Filardo EJ, Dong J (2005) Identity of an estrogen membrane receptor coupled to a $\mathrm{G}$ protein in human breast cancer cells. Endocrinology 146:624-632.

Vanderhorst VG, Terasawa E, Ralston HJ 3rd (2009) Estrogen receptoralpha immunoreactive neurons in the brainstem and spinal cord of the female rhesus monkey: species-specific characteristics. Neuroscience 158:798-810.

Vasudevan N, Pfaff DW (2008) Non-genomic actions of estrogens and their interaction with genomic actions in the brain. Front Neuroendocrinol 29:238-257.

Vivacqua A, Bonofiglio D, Recchia AG, Musti AM, Picard D, Andò S, Maggiolini M (2006) The G protein-coupled receptor GPR30 mediates the proliferative effects induced by 17 beta-estradiol and hydroxytamoxifen in endometrial cancer cells. Mol Endocrinol 20:631-646.

Zeps N, Bentel JM, Papadimitriou JM, D’Antuono MF, Dawkins HJ (1998) Estrogen receptor-negative epithelial cells in mouse mammary gland development and growth. Differentiation 62:221-226. 